\title{
Sharing the Costs of Humid Region Flood Control Investment
}

\author{
Ayers Brinsen*
}

\begin{abstract}
TTHE title of this paper suggests the question: what, if any, characteristics of the humid regions have a unique impact on sharing costs of flood control investments? Would these characteristics impose any restrictions on or require extensions of conventional economic criteria for cost sharing? Certainly the contrast of the physical environment of the East with that of the arid West requires different techniques of water management. With a larger, more concentrated population, older and more extensively developed private investments, and the complex institutional commitments that have evolved with them, the means for achieving efficiency and equity in cost sharing also may not be the same as those that would apply in the arid West. In the East, the closer and more in-plains, storage areas, and water use demand that investments in stream management be scheduled and integrated with scrupulous observation of their impact both in the present and over time if acceptable levels of efficiency and standards of equity are to guide flood control investments.
\end{abstract}

This suggests that there is a significant dichotomy between the humid East and the arid West. However, more important than those obvious distinctions is the difference in the attitude of public policy vis à vis the arid West and the humid East. Public investment has been a substantial element in the development of the West. Until recently, private investment in water resource use and associated activities was the dominant pattern in the East. Today further economic and social development east of the Mississippi depends in increasing measure on new and substantial investments by federal, state and local governments as well as by quasi-public agencies such as watershed districts. Not only are new sources of funds required, but there is a growing need for public goods and services to complement private investment and to stimulate growth. These are essential if, in the East, full responsibility for improving the quality of the economic and social environment is to be accepted and implemented. Thus, the problems associated with cost sharing arise not only from the need for new and larger investment, but also from adapting the criteria of efficiency and equity to accomplish fundamental changes in deeply imbedded attitudes.

- I am indebted to Lee Martin for a critical reading of this paper.

AYERS BRINSER is professor of resource economics and environmental health, University of Michigan. 
There are far too many of these necessary changes even to catalogue them in a discussion of this length. Furthermore, while the canon of cost benefit doctrine is both extensive and sophisticated, cost allocation, cost sharing, and assessment of charges have been left in economic limbo. Consequently there is a very small body of common knowledge which such a discussion could assume. For these reasons, what follows will be restricted to two obvious categories of issues, one economic and the other institutional, as they relate to the humid East.

\section{Economic Issues}

It must also be recognized that to isolate cost sharing from the array of interdependent decisions such as cost allocation, timing of investment and joint costs is at best a partial view of an issue that can be assessed only in terms of the whole. Thus what is said here concerning cost sharing must assume that these other aspects of the investment decision can be ordered to be consistent with the criteria for cost sharing. Admittedly, to achieve such an ordering is the major issue in investment decision. Establishing criteria for cost sharing is necessary. It certainly is not sufficient nor even relevant if it is not adapted to the other aspects of investment decision.

In general terms, public policy for cost sharing is designed to satisfy these criteria: to induce optimum resource development and to promote some predetermined pattern of distribution of benefits over time. The device recommended for achieving these criteria recommended by the subcommittee on benefits and costs of the Federal Interagency River Basin committee is the doctrine of separable costs remaining benefits. When there are conflicts between these objectives, it is assumed that friction can be minimized by relating the incidence of benefits to the incidence of costs. Specifically, cost sharing should: (1) Contribute to the efficient use of resources. In this it is a supporting instrument of the cost benefit ratio which is fundamentally concerned with efficiency of production. (2) Provide for patterns of cost distribution that will promote public policy objectives such as sustaining family size farms, resource conservation, economic stability, and economic development. (3) Minimize windfall gains. (4) Encourage a distribution of costs and returns in accord with basic welfare criteria. In order to do all these things there must be consistent standards for the division of responsibility. As Mark Regan has remarked, cost sharing is in essence, "Financial responsibility distribution."

In making flood control investments with necessarily long payoff pe-

\footnotetext{
${ }^{1}$ Mark Regan, "Sharing Responsibility in River Basin Development," J. Farm Econ., Vol. 40, December 1958, p. 1690.
} 
riods there must be assurance of continuity of financial responsibility. Particularly in the East, where the relationship between public and private investment in water resources is highly interdependent and where the balance between these two sources of funds is shifting, some provision must be made for the reallocation of water uses and services and shifts among the interests and groups served. Among the more important of these are reinterpretations of the legal rights to the uses and services of water. What is clearly implied here is that investment in flood control must be construed as a part of an integrated and interdependent set of services such as recreation, industrial and municipal water supply and quality, and landscape enhancement. With new water management agencies in the East and with new and broader interest in water resource development by existing agencies, it is particularly important not only that criteria for cost sharing be standardized, but also that the impact and distribution of cost sharing schemes be integrated so that they have a cumulative effect on economic and social development.

Conventionally, there are two ways to determine who should pay what cost. The first is to assign charges on the basis of project cost. This method is most useful when the services are provided by private investment and they are vendible at freely determined market prices. The second approach is to base charges on the value of project services. If the project is to produce an array of services over time, and public values are important, this method has certain significant advantages. If it is granted that in the East both public and private investment are necessary to sustain economic growth, then the first criteria in selecting a method in cost sharing should be what kind of development will it stimulate and who is to be responsible for setting it in motion. This means accepting the criterion of efficiency as only one, not the primary measure for choosing among investment alternatives.

\section{Cost Sharing on the Basis of Project Cost}

Assigning cost shares on the basis of project cost has certain very clear advantages. It provides an easy way for determining what people would be willing to pay for the developed services, In addition, if there were full reimbursement for secondary benefits that otherwise would be excluded from the project, then the useful scope of the developments could be expanded to include such worthwhile activities. In the East where flood control projects may involve relatively small local development with secondary benefits, this method would be very useful to bring such local activities into the development program. In addition, where public and private investments in a given project are to be combined, a system of cost sharing based on private project costs would offer a means of 
combining the two sources of funds as complementary. In the case of recreation associated with flood control design, the system of charges based on costs would provide a rational connection between beneficiaries and investors. The opportunity to recover the full cost of vendible services would create a clear incentive for increasing private investment in needed recreation resource development. With net returns available for future investment, the rate of increasing the supply of recreation facilities could be positively connected with demand. This is in essence what the new Land and Water Resources Act will attempt to achieve.

If this method of cost sharing is used, separable costs of development projects must be identified and quantified. Where there are joint fixed costs, the problem of assignment can be reasonably satisfied by a distribution of joint costs in proportions to the benefits assuming that the latter can be revealed by the acceptance of charges based on separable costs.

The important disadvantages of cost sharing based on project cost are those that influence the rate and kind of project development and the direction of development over time. The fact that a given group of people is willing to pay the cost of certain project services is no guarantee that an allocation of scarce funds to provide such services will yield the highest feasible net social values or in some cases the best private returns. By the same token, the ease of collecting costs is in itself an inadequate measure of total value produced. Many critical values that are now ignored or given short shrift in the East would not come up for critical evaluation if these standards were imposed. The same argument would apply to the criterion of present ability to pay for development. In the case of recreation, a supply-demand equation will not necessarily lead to an optimum resource allocation. The underlying intention of public investment in recreation is to create a fuller range of values from the natural landscape. To do this it must provide a larger supply to stimulate more socially desirable demand. A comparably parallel problem is how to relate a cost sharing calculation based on cost recovery to an investment program to increase the value of recreation and enhancement of the landscape for the purpose of accelerating economic and social development?

Perhaps the general problems arising from assigning charges on the basis of projected costs are best revealed by the issues related to windfall gains. Considerations of both equity and efficiency dictate that windfall gains such as enhanced real estate values from flood plain protection should be recaptured to reimburse the associated costs. But that is only the superficial aspect of the real problem as it relates to flood control investment. The basic intention of such investment should be to avoid external diseconomies, and equally important from the point of view of 
this paper, to create external economies. To be sure, the gains from external economies should go to those who pay the costs and or can convert those gains to the highest total net benefits through future investments. A system of cost sharing that would prevent opportunities for external economies or create external diseconomies should be replaced by one that would enhance the possibilities for greater external economies and inhibit external diseconomies when compensation would not be justified. (To say this, of course, leaves unanswered the larger question of how such costs and returns may be measured.) Cost sharing based on project costs could only be adapted with great difficulty to those ends.

\section{Charges and Assessments Based on Value of Services}

The chief advantage of charges based on the value of services is that they are more effective in situations where the objective is to create general social values and economic development. This system avoids many of the problems of determining specific costs and making precise estimates of national public benefits. One particular virtue of this method in a region with a developed economy is its flexibility. Adjustments of charges can be made to stimulate development as conditions change. Advantages can be given to particular purposes as the need for them becomes apparent. Charges could be based on the real or purchasing power of benefits rather than money costs; thus the recovery costs would be in real terms. This is particularly important in flood control projects with a long payoff, and where investments induce a stream of substantial economic changes as is likely in the humid East. Furthermore, with repayment based on ability to pay, the chances of recapturing costs may be greater.

To return to the problem of windfall gains, under this method charges would be assigned without regard to project costs. Instead they would be based on the identifiable beneficiaries and the magnitude of the benefits. If the returns do not equal the costs or if there are external diseconomies, the public obligation for such costs could be determined. In combination with the measure of benefits, this cost is an important factor in assessing the total value or opportunity costs of alternative projects. Thus the costs and returns from investments to maximize external economies or minimize external diseconomies are explicitly revealed to be weighed in the process of choosing among alternative projects. One element of this choice is to decide how to collect and allocate values produced in excess of those needed to reimburse beneficiaries. If we should adopt some form of performance budget for flood control and associated projects, the measurement of these excess values will have a large role to play in designing future project investment. In the East 
where public investment to support economic and social development should be increasingly significant, this would be a major consideration. Investment for recreation and pollution control are two immediately apparent examples where this could apply.

In situations where investments are needed as incentives to better water resource development, costs based on benefits can be used as incentives to support such development. These changes could be adjusted to compensate for risks and to stimulate creation of the social values predicted to flow from such projects.

The major disadvantage of assigning costs on the basis of the value of services is the opportunity it opens up for shifting costs that should be borne by identifiable beneficiaries to the public. Ciriacy-Wantrup has suggested that supply and demand functions could be constructed for these services. The costs should be based on the separable costs of the services rather than the project costs. ${ }^{2}$ Particularly where there is a mixture of public and private investment, judgment in addition to quantification would still be an essential ingredient in the equations.

Inherently in any system it is not easy to compare private and public values when these are produced jointly. Two difficulties given major weight by Krutilla and Eckstein in their Multiple Purpose River Development are those of combining differences in the cost of money and differential tax liabilities. ${ }^{3}$ McKeans' system of measurement by internal rates of return may offer a way out.*

\section{Institutional Issues}

The major institutional issue in designing cost sharing systems is to establish comparable standards of efficiency and equity in resource development agencies. From the point of view of these agencies, it is essential to maintain a clientele. When a given agency charges lower costs, or has a system with greater advantages to cost sharers, or shifts costs to a collective public and distributes gains to grateful beneficiaries, it strengthens its position in securing appropriations and the extension of its program. This is a political fact of life that must be reckoned with in designing cost sharing schemes; it simply will not disappear before the onslaught of pious exhortations for absolute efficiency and equity. It is

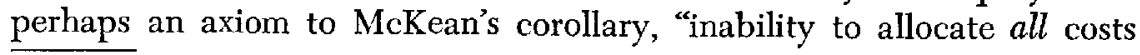

${ }^{2}$ Ciriacy-Wantrup, "Cost Allocation in Relation to Western Water Policies," $J$. Farm Econ., February 1954, p. 120.

"John Krutilla and Otto Eckstein, "The Willemette River Case," Multiple Purpose River Development, Baltimore, Johns Hopkins Press, pp. 234-264.

${ }^{4}$ For a caveat on this possibility see G. S. Tolley, "McKean on Government Efficiency," Rev. Econ. and Stat., Vol. 41, November 1959, pp. 446-448; and Tolley, "Analytical Techniques in Relation to Watershed Development," J. Farm Econ., Vol. 40, August 1958, pp. 653-665. 
meaningfully on joint products is often a fact of life not a sign of dis-

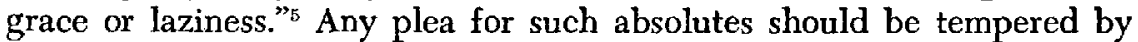
the knowledge that the opportunity to make real choices among different programs is a basic element of consumer freedom. In the East where new programs and new project designs must be developed, this choice among alternative programs gives essential freedom in the process of evolving more effective water resource programs.

This is not to say that cost sharing systems should not be integrated. The problem is to use standards to guide such integration that will maintain flexibility and reasonable choice along with necessary efficiency and equity. It must be remembered that cost sharing systems influence who shall invest, what kind of projects will be built, when, at what scale, and what the alternative choices in the future may be.

One of the differences that could be adjusted among government agencies and between government and private agencies is the variation of the accounting costs as they affect methods of financing and repayment. Another is to adopt differences in the distribution of gains to meet individual, group, and social objectives. This is particularly important in projects where private and public investment are combined. Quite justifiably some benefits will be distributed to enhance social preferences while private benefits are awarded usually to the highest bidder without regard to the social quality of the services produced. The form of payments should be reconciled with the project objectives and the clientele. Charles Lindblom's dictum in regard to public policy objectives is relevant here, "Not only . . . does public policy often not aim directly at one satisfaction it aims instead at creating conditions in which appropriate want satisfying activity will be called forth from the individual.' In this we are concerned with values not as a total or average values, but instead values at the margin. ${ }^{6}$

In general the institutional issues are those related to minimizing conHicts among investing agencies and interest groups and in directing investment toward projects that are not only presently efficient, but which will stimulate development and improve net welfare over time. In the East this calls for something more than agreement on a set of principles of economic rectitude. It means rather designing cost sharing systems that will assist the development of projects to sustain economic and social growth in which efficiency and equity are essential parts but

${ }^{5}$ Roland and McKean, Efficiency in Governmental Systems Analysis, New York, John Wiley and Sons, 1958, p. 46.

"Charles E. Lindblom, "The Handling of Norms in Policy Analysis," The Allocation of Economic Resources, M. Abramowitz (ed.), Stanford University Press, 1959, pp. 169-171. 
not the whole. The present state of theory suggests that the available tests of usefulness are largely pragmatic.

This brief and by no means complete catalogue of issues surrounding cost sharing cannot hope to have provided any answers. Our serious concern with these issues is so recent and so limited that we have not yet clearly identified the relevant questions.? At least it is now becoming clear that the time has come to consider the issues surrounding cost sharing as critical elements in designing a resource management and policy program that will meet both the efficiency and welfare objectives of the private and public economy.

${ }^{\top}$ There are exceptions. See for example, Mark Regan, op. cit., and his "Economically Desirable Institutional Arrangements and Cost Sharing Requirements," Economics of Watershed Planning, G. S. Tolley and F. E. Riggs (eds.), Iowa State Univ. Press, 1961, pp. 230-245. See also Michael F. Brewer, Economics of Public Water Pricing, California Agr. Expt. Sta., Giannini Foundation Research Report No. 244, May 1961. 